\title{
Skeletal muscle phenotypes initiated by ectopic MyoD in transgenic mouse
}

\section{heart}

\author{
JEFFREY H. MINER ${ }^{1}$, JEFFREY B. MILLER ${ }^{2}$ and BARBARA J. WOLD ${ }^{1, *}$ \\ ${ }^{1}$ Division of Biology 156-29, California Institute of Technology, Pasadena, CA 91125, USA \\ ${ }^{2}$ Cecil B Day Laboratory for Neuromuscular Research, Massachusetts General Hospital, Charlestown, MA 02129; and Program in \\ Neuroscience, Harvard Medical School, Boston, Massachusetts 02115, USA \\ *To whom correspondence should be addressed
}

\begin{abstract}
Summary
Forced expression of the myogenic regulatory gene MyoD in many types of cultured cells initiates their conversion into skeletal muscle. It is not known, however, if MyoD expression serves to activate all or part of the skeletal muscle program in vivo during animal development, nor is it known how limiting the influences of cellular environment may be on the regulatory effects of $\mathrm{MyoD}$. To begin to address these issues, we have produced transgenic mice which express MyoD in developing heart, where neither MyoD nor its three close relatives - myogenin, Myf-5, and MRF4/herculin/Myf-6 - are normally expressed. The resulting gross phenotype in offspring from multiple, independent transgenic founders includes abnormal heart morphology and ultimately leads to death. At the molecular
\end{abstract}

level, affected hearts exhibit activation of skeletal muscle-specific regulatory as well as structural genes. We conclude that MyoD is able to initiate the program that leads to skeletal muscle differentiation during mouse development, even in the presence of the ongoing cardiac differentiation program. Thus, targeted misexpression of this tissue-specific regulator during mammalian embryogenesis can activate, either directly or indirectly, a diverse set of genes normally restricted to a different cell lineage and a different cellular environment.

Key words: MyoD, myogenin, transgenic mice, myogenesis, skeletal muscle development, heart.

\section{Introduction}

MyoD (Davis et al., 1987; Tapscott et al., 1988) is a member of the basic/helix-loop-helix family of myogenic regulatory, sequence-specific DNA binding proteins, which are expressed solely in skeletal muscle cells and their precursors (Olson, 1990; Emerson, 1990; Weintraub et al., 1991). When a transfected gene encoding MyoD or any of its three relatives - myogenin (Wright et al., 1989; Edmondson and Olson, 1989), Myf-5 (Braun et al., 1989b), and MRF4/herculin/Myf-6 (Rhodes and Konieczny, 1989; Miner and Wold, 1990; Braun et al., 1990) - is expressed in cultured fibroblasts, the cells become competent to differentiate into skeletal muscle when subjected to the proper environmental cues. MyoD is also able to initiate conversion to skeletal muscle of a wide variety of cultured cell types, including fat, liver, cartilage, nerve, smooth muscle, and pigment (Davis et al., 1987; Weintraub et al., 1989; Choi et al., 1990), but the extent of myogenic conversion varies and appears to be dependent on cell host (Davis et al., 1987; Weintraub et al., 1989) and on cell history (Schafer et al., 1990). In addition, drastic changes in the growth factor content of the culture medium are required for cells transfected with $\mathrm{MyoD}$ to differentiate into skeletal muscle (Florini and Magri, 1989). Finally, ectopic expression of Xenopus MyoD and Myf-5 homologues in isolated Xenopus embryo animal caps is not sufficient to establish a substantial, stable, skeletal muscle phenotype (Hopwood and Gurdon, 1990; Hopwood et al., 1991), underscoring the significance of cell history and environment in determining whether and to what extent ectopic expression of a myogenic regulator can initiate skeletal myogenesis.

The expression patterns of the MyoD family members during mouse embryogenesis has been determined by in situ hybridization (Sassoon et al., 1989; Ott et al., 1991; Bober et al., 1991; Hinterberger et al., 1991). While each myogenic regulatory gene is expressed in a unique temporal and spatial pattern (suggesting possible functional differences), all are restricted to skeletal muscle and to skeletal muscle precursors. Taken together with the powerful activities of the myogenic regulators when transfected into cultured cells, their expression in embryonic muscle precursors is good 
circumstantial evidence that these genes serve to initiate skeletal myogenesis during mammalian development. However, as yet there is no direct evidence to support this hypothesis.

With this study, we have begun to directly address questions concerning the function of MyoD during development by using targeted expression of MyoD in transgenic mice. This approach has allowed us to evaluate the regulatory potential of MyoD outside the environment of the tissue culture dish and free of the effects of the unknown genetic changes exhibited by most established cell lines. Our results show that expression of $\mathrm{MyoD}$ is sufficient to initiate ectopic skeletal muscle differentiation in cardiac tissue of the developing mouse embryo.

\section{Materials and methods}

\section{Construction of the transgene and production of transgenic mice}

$\mathrm{pEt}$, which contains the $3.3 \mathrm{~kb}$ mouse muscle creatine kinase (MCK) enhancer/promoter element inserted into EcoRI and SmaI cut pUC 118, was a gift from Jean Buskin (Univ. of Washington, Seattle). The $2 \mathrm{~kb} \mathrm{RsaI}$ to $\mathrm{XbaI}$ fragment of pEMc11s (Davis et al., 1987), which contains the MyoD coding region and SV40 T-antigen $3^{\prime}$ processing signals, was inserted downstream of the MCK promoter at the $X b a I$ site of $\mathrm{pEt}$ via a ligate-blunt-ligate procedure. The resulting plasmid was purified by equilibrium centrifugation in a $\mathrm{CsCl}$-ethidium bromide gradient and cut with Sall. This liberated a $4.8 \mathrm{~kb}$ fragment containing $2.8 \mathrm{~kb}$ of $\mathrm{MCK}$ regulatory sequences, the MyoD coding region, and the SV 40 sequences (Fig. 1). This fragment was separated from vector sequences by agarose gel electrophoresis (Johnson et al., 1989), dissolved in $10 \mathrm{mM}$ Tris- $\mathrm{HCl} \mathrm{pH} 7.5,0.1 \mathrm{mM}$ EDTA, and microinjected into pronuclei of single cell mouse embryos (Hogan et al., 1986) derived from a (C57BL/6 $\times$ DBA $/ 2) \mathrm{F}_{1} \times(\mathrm{C} 57 \mathrm{BL} / 6 \times \mathrm{DBA} / 2)$ $F_{1}$ cross. Potential founders were screened by Southern blot using tail DNA.

\section{RNA isolation and analysis}

Fetal limbs and hearts were frozen at $-80^{\circ} \mathrm{C}$ until genotypes could be determined by Southern blot using fetal tail DNA. Hearts of like genotype (transgenic or wild-type) were pooled to assure adequate RNA yields. RNA was prepared by acid guanidinium-phenol extraction (Chomczynski and Sacchi, 1987) and analyzed by neutral agarose gel electrophoresis to verify both the quantity and the quality of the RNA. Ribonuclease protection assays were performed as described (Miner and Wold, 1991) with the following ribonuclease conditions: for myogenin, $1000 \mathrm{U}$ of RNase $\mathrm{T} 1$ (US Biochemical Corp.) per ml; for the other probes, $1000 \mathrm{U}$ of RNase T1 plus $0.36 \mathrm{ng}$ RNase A (Sigma) per ml.

\section{Probes for ribonuclease protection assays}

The MCK probe used was from exon 7 (Johnson, 1988). The MyoD and myogenin probes were as described (Miner and Wold, 1991), except that the restriction cut for linearizing the MyoD template was at DdeI (nucleotide 1563 in Davis et al., 1987). The template for the sarcomeric actin riboprobe was synthesized by polymerase chain reaction amplification of mouse heart cDNA using one primer containing both the $T 7$ RNA polymerase promoter (underlined) and sequences complementary to the unique $3^{\prime}$ untranslated region of the cardiac $\alpha$-actin isoform mRNA (5'-GTAATACGACTCACTATAGGAGGATTCCAAGAAGCACAATACG- $3^{\prime}$ ), and a second primer from its coding region (5'-GCAAAAGGAAATCACTGCACTGG-3'), which is very conserved between cardiac and skeletal $\alpha$-actin isoforms (Leader et al., 1986). Cardiac $\alpha$-actin mRNA protects the entire probe, whereas the skeletal isoform mRNA protects only coding region sequences, thus producing discrete bands.

\section{Cryosectioning and immunostaining}

Dissected hearts were immediately placed into O. C. T. Compound and frozen into blocks on dry ice. $10 \mu \mathrm{m}$ sections were cut on a cryostat, collected on subbed slides, and air dried. Two twelve-hour incubations with hybridoma supernatants were performed at room temperature in a humidified chamber, followed by a six-hour incubation with FITClabeled goat anti-mouse secondary antibody.

\section{Western blot analysis}

Hearts were individually homogenized in $50 \mu \mathrm{l}$ of high salt solubilization buffer (Evans et al., 1988), and the supernatants were mixed with an equal volume of glycerol. Myosin heavy chain (MHC) isoforms were analyzed by SDS-PAGE in $6 \%$ polyacrylamide, $37.5 \%$ glycerol gels (Schiaffino et al., 1989; Smith and Miller, 1992) followed by immunoblotting with: monoclonal antibody (mAb) F59, which reacts with all skeletal and cardiac MHC isoforms; mAbs $10 \mathrm{C} 2$ and BF-45, which are specific for the embryonic MHC isoform; mAb BF34 , which is specific for the perinatal MHC isoform; or mAb F47, which reacts with perinatal and adult Type II MHC isoforms (Evans et al., 1988; Schiaffino et al., 1988; Miller, 1990; Smith and Miller, 1992). Monoclonal antibodies BF-34 and BF- 45 were gifts from S. Schiaffino, and $\mathrm{mAb} 10 \mathrm{C} 2$ was a gift of $\mathbf{J}$. Leger. Binding of mAbs was detected with a horseradish peroxidase detection system (Vectastain $A B C$ Kit) using a diaminobenzidine or chemiluminescent substrate.

\section{Results}

\section{Production and characterization of transgenic mice}

Transgenic mice that carry the MyoD protein coding sequence (Davis et al., 1987) under the control of the mouse muscle creatine kinase (MCK) enhancer/promoter element (Jaynes et al., 1988) were produced. A map of this construct is depicted in Fig. 1. Based on prior transgenic mouse studies of MCK regulatory sequences linked to a bacterial chloramphenicol acetyltransferase reporter gene (Johnson et al., 1989), we expected this element to direct overexpression of MyoD in skeletal muscle and ectopic expression in

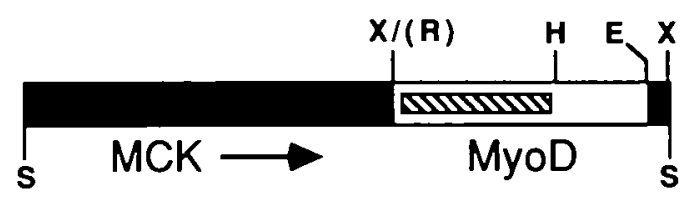

Fig. 1. Restriction map of the $4.8 \mathrm{~kb}$ Sall microinjection fragment used to produce the transgenic mice. Stippled bar, $2.8 \mathrm{~kb}$ MCK regulatory region; white bar, $1.8 \mathrm{~kb}$ MyoD cDNA; hatched bar, MyoD protein coding region; black bar, $0.24 \mathrm{~kb} S V 40 \mathrm{~T}$-antigen polyadenylation signal sequences. S, SaII; X, XbaI; R, RsaI; H, HindIII; E, EcoRI. 
Table 1. Transgenic founder mice and summary of breeding data

\begin{tabular}{lccc}
\hline $\begin{array}{l}\text { Transgenic } \\
\text { founder }\end{array}$ & Sex & $\begin{array}{c}\text { Transgenic } \\
\text { pups }\end{array}$ & $\begin{array}{c}\text { Transgenic } \\
\text { fetuses }\end{array}$ \\
\hline MuD 14 & M & - & + \\
MuD 18 & F & - & $?$ \\
MuD 20 & F & + & + \\
MuD 28 & F & - & + \\
MuD 30 & F & - & $?$ \\
MuD 42 & M & - & + \\
MuD 50 & M & - & + \\
\hline
\end{tabular}

cardiac muscle; cardiac muscle is structurally, functionally, and developmentally distinct from skeletal muscle and normally expresses none of the MyoD family regulators. Thus, the heart provides a good cellular context for examining the ability of MyoD to activate skeletal muscle-specific genes where they are normally destined to be silent.

Seven transgenic founder mice are listed in Table 1. Six of these did not produce live transgenic pups, though all were fertile. This indicated that either the transgene was absent from the germline of these six founders or that their transgenic offspring were dying before birth. Indeed, when offspring of four of these six founders were examined in utero, transgenics were discovered, suggesting that the transgene was associated with embryonic lethality in these cases. More detailed studies revealed that transgenic fetuses in several litters sired by founders $\mathrm{MuD} 14, \mathrm{MuD} 42$, and MuD 50 were dying at 16-18.5 days of gestation (E16E18.5) and as early as E15.5 had visibly misshapen hearts (Fig. 2). Transgenic hearts did beat, but when removed from the fetus they were unable to fully pump blood out of both ventricles, although hearts from their wild-type (WT) littermates could do so. That viable transgenic founders were obtained at a frequency normal for microinjection (Hogan et al., 1986) suggests that either many founders did not express the newly introduced transgene, or that they were often genotypically mosaic in the heart. The MuD 30 founder, for example, was found to contain less than one copy of the transgene per cell in heart, liver, and tail. In addition, MuD 14, 42, and 50 founders all appeared to be mosaic in the germ-line (and therefore perhaps in other tissues as well), transmitting the transgene to offspring at a frequency of only $10-30 \%$ (J. H. M., unpublished observations).

\section{Expression of $M y O D$ and its downstream effects}

These transgenic animals allowed us to test the ability of MyoD to act in the animal at the molecular level. Expression of the transgene and various cardiac and skeletal muscle genes was measured in hearts and whole limbs (representing skeletal muscle) of transgenic fetuses and WT littermate controls (Fig. 3). The endogenous MCK gene was expressed in both WT and transgenic heart and limb. As anticipated (Johnson et al., 1989), the transgene, which contained the MCK enhancer/promoter, was expressed in transgenic heart and limb (lanes 3, 4, 7, and 8). Limb skeletal muscle expressed endogenous MyoD in all cases, as expected, but transcripts from the endogenous MyoD gene were not detectable in transgenic hearts (lanes 3 and 7). Thus, in cardiac tissue, ectopic MyoD does not positively regulate its endogenous counterpart, a result also obtained with MyoD-transfected NIH 3T3 cells (Thayer et al., 1989; Miner and Wold, 1990) but in contrast to the autoactivation observed in transfected C3H 10T1/2 cells (Thayer et al., 1989). Ectopic MyoD also failed to trigger detectable expression of Myf-5 or MRF4/herculin/Myf-6 in transgenic hearts (data not shown), but myogenin expression was clearly activated (lanes 3 and 7). This activation may be biologically significant, because myogenin is the only myogenic regulator to have been detected in all differentiated

\section{Wild-Type}

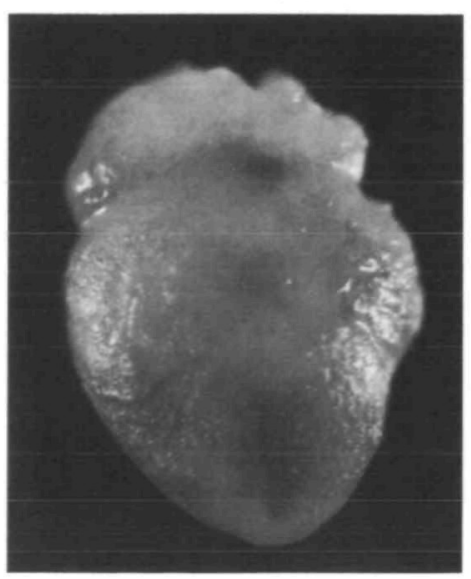

MuD 42

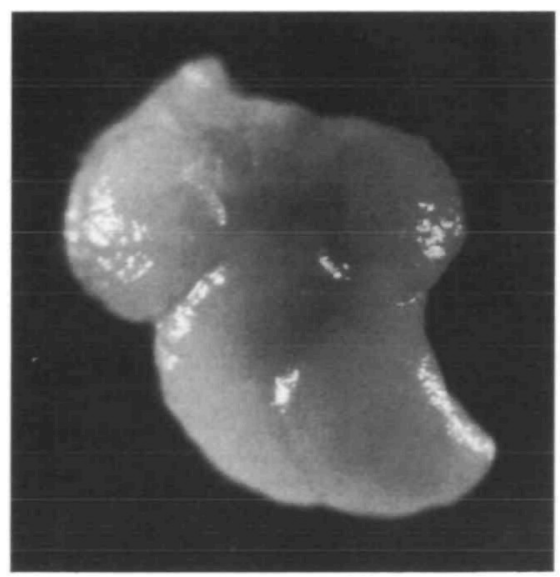

MuD 50

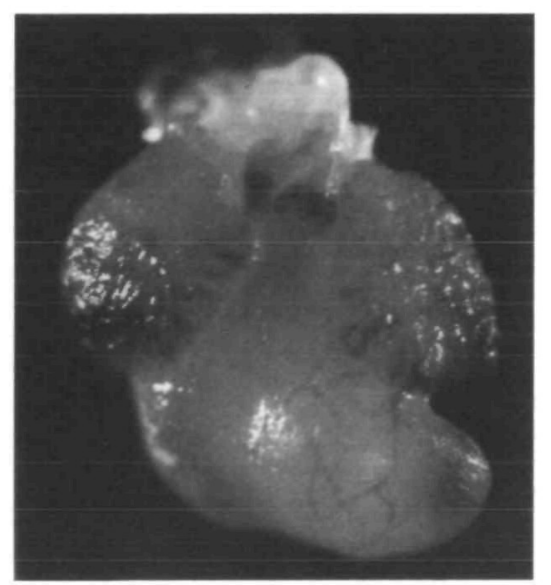

Fig. 2. Transgenic fetuses have malformed hearts. All hearts shown were dissected from $\sim$ E17 fetuses, fixed in $3.5 \%$ formaldehyde in phosphate-buffered saline, and photographed frontally. The MuD 50 heart morphology is representative of that exhibited by MuD 14 hearts. Transgenic ventricles have over-defined apices which point towards the right (i. e., towards the left atrium), whereas WT ventricle is more smoothly shaped and points down, away from the atria. 

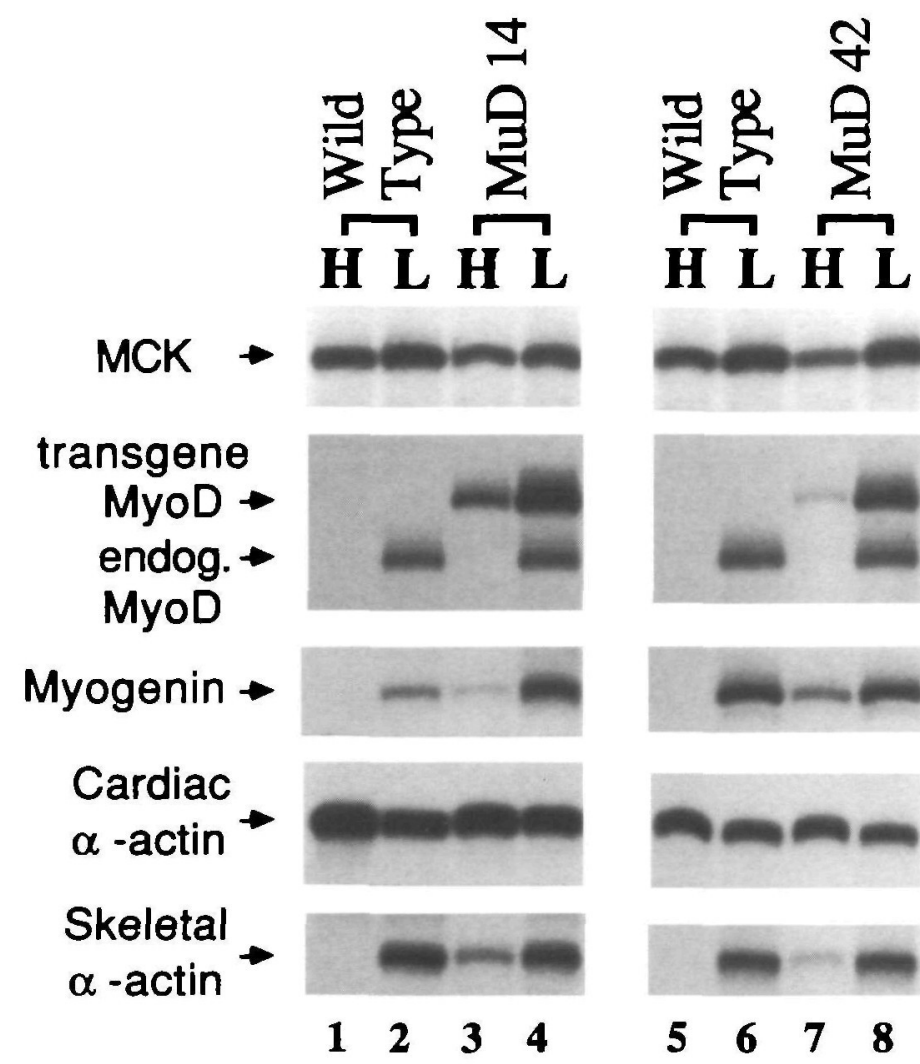
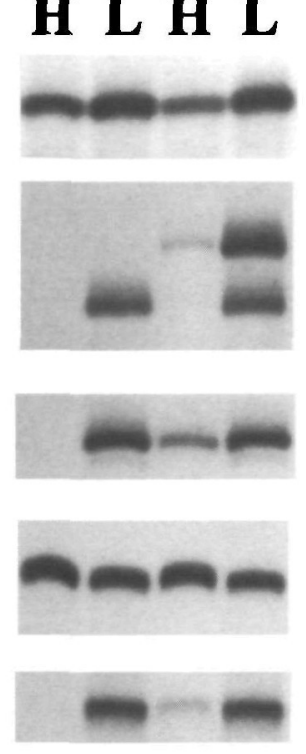

$5 \quad 6 \quad 7 \quad 8$

Fig. 3. Ribonuclease protection analyses of expression patterns of the indicated genes. H, heart; L, limb (both whole). Transgenic hearts differ from WT in their expression of MyoD, myogenin, and skeletal $\alpha$-actin. RNAs used in WT companion lanes are from littermates of transgenics. MuD 14 but not MuD 42 limb appears to overexpress myogenin relative to the companion WT limb, though corresponding MCK and $\alpha$-actin levels are comparable. MuD 14 and WT companion RNA preparations were made from E18.5 tissues, except the MyoD assay used RNA from E16.5 tissues (E18.5 tissues gave similar results for MyoD.). All MuD 42 and WT companion RNA preparations were made from E16.0 tissues. Amounts of total RNA used were: for MCK and $\alpha$-actins, $1 \mu \mathrm{g}$ heart RNA and $3 \mu \mathrm{g} \operatorname{limb} \mathrm{RNA}$; for MyoD and myogenin, $8 \mu \mathrm{g}$ heart RNA and $15 \mu \mathrm{g}$ limb RNA. In a similar experiment, long exposures revealed very low levels of transgene expression in liver and brain, and appreciable levels were found in lung (data not shown); however, the latter may be due to contaminating cardiomyocytes which are known to migrate into the lung through pulmonary blood vessels (Kramer Jr. and Marks, 1965).

skeletal muscle cells in culture (Olson, 1990; Emerson, 1990 ) and thus may be essential for expression of the differentiated skeletal muscle phenotype. Hearts of the MuD 20 line, which showed no visible phenotype and no lethality, expressed an aberrant MyoD transcript and did not express myogenin (data not shown).

Since the contractile machineries of cardiac and skeletal muscle consist of different (though partially overlapping) sets of proteins, we were interested to discover whether expression of MyoD and myogenin in the heart led to alterations in the repertoire of

contractile protein genes expressed. As shown in Fig. 3, fetal skeletal muscle (lanes 2 and 6 ) normally expresses both the cardiac and skeletal $\alpha$-actin genes, whereas expression of the cardiac but not the skeletal isoform is normally detected in fetal heart (lanes 1 and 5). However, in transgenic hearts which expressed MyoD and myogenin, RNA from the skeletal $\alpha$-actin gene was detected (lanes 3 and 7), whereas the levels of cardiac $\alpha$-actin RNA expressed in transgenic hearts and limbs appeared similar to wild-type. The most straightforward interpretation of skeletal $\alpha$-actin expression in transgenic hearts is that ectopic MyoD led to an upregulation of skeletal $\alpha$-actin gene expression, as occurs in MyoD-transfected NIH 3 T3 fibroblasts (J. H. M., unpublished observations). Alternatively, since skeletal $\alpha$-actin is expressed in the absence of MyoD very early in the developing heart (Sassoon et al., 1988) and in hypertrophic adult hearts (Schwartz et al., 1986), the observed elevation of skeletal $\alpha$-actin RNA may be secondary to physiological effects caused by the morphological abnormalities. To clarify this point, other skeletal markers that should not be subject to this qualification were examined. Myosin heavy chain (MHC) isoform expresssion was analyzed by indirect immunofluorescence on frozen sections (Fig. 4) and by western blotting (Fig. 5) using MHC isoform-specific monoclonal antibodies (mAbs). Immunostaining analysis showed that a non isoform-specific MHC antibody reacted with the musculature of both wild-type and transgenic hearts (Fig. 4A,B), whereas a mAb specific for the embryonic MHC isoform reacted with transgenic (Fig. 4D) but not with WT (Fig. 4C) heart. The embryonic MHC isoform is normally specific to skeletal muscle. Staining was restricted to portions of the ventricle, but we do not yet know whether this reflects a corresponding pattern of MyoD expression. (A similar pattern was observed using an antibody against nebulin, another skeletal muscle-specific sarcomere component [data not shown]). The staining results were confirmed by the western blot analyses (Fig. 5), which showed that both MuD 14 and MuD 42 transgenic hearts produced the embryonic MHC isoform. The MuD 42 transgenic heart expressed an additional skeletal muscle-specific $\mathrm{MHC}$, the perinatal MHC isoform. We conclude that MyoD is able to initiate activation of skeletal musclespecific genes in a developing tissue, implying that it may indeed have a similar role in developing skeletal muscle.

\section{Discussion}

These experiments establish that $\mathrm{MyoD}$ can function as an initiator of the skeletal muscle differentiation program in the developing embryo. Thus, the myogenic activity of MyoD is not limited to environments specified by cell culture transfection studies, but extends to intact, developing tissue. Because in vitro DNA binding studies show that MyoD family proteins, when oligomerized with helix-loop-helix proteins of the E2 family, can efficiently bind sites of known functional 

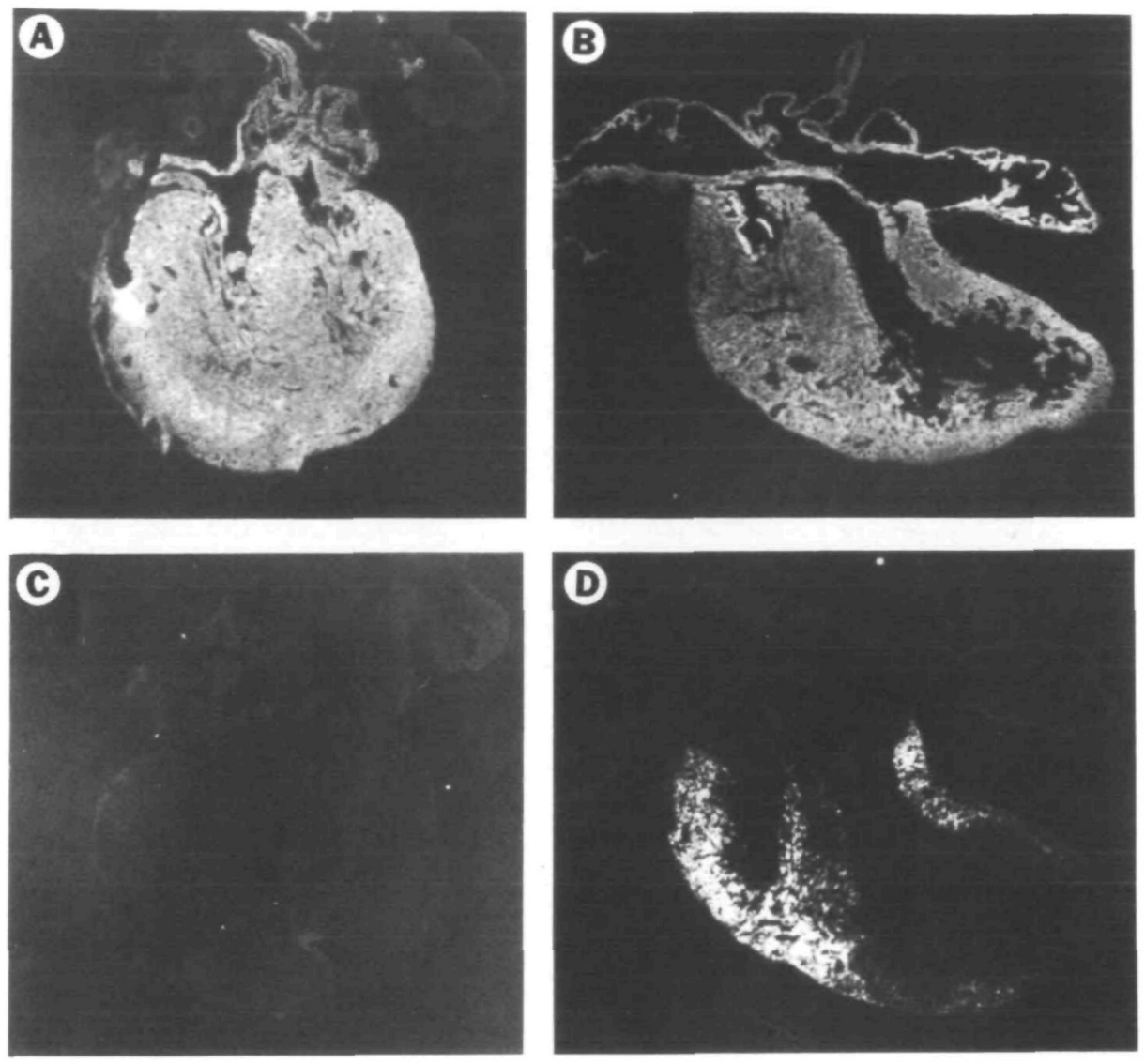

Fig. 4. Indirect

immunofluorescence using either (A, B) a general MHC monoclonal antibody (Laird and Revel, 1991) or (C, D) the skeletal muscle-specific embryonic MHC mAb $10 \mathrm{C} 2$ (a gift from J. Leger). $10 \mu \mathrm{M}$ frozen sections of MuD $14 \mathrm{E} 16$ heart $(B, D)$ and a WT control heart $(A, C)$ were used. While the nonspecific $\mathrm{MHC}$ mAb labels all atrial and ventricular musculature, only transgenic ventricle is reactive with the embryonic $\mathrm{MHC}$ isoform $\mathrm{mAb}$. importance in skeletal muscle-specific enhancers (Lassar et al., 1989; Braun et al., 1990; Brennan and Olson, 1990; Davis et al., 1990; Piette et al., 1990; Rosenthal et al., 1990; Sartorelli et al., 1990; Braun and Arnold, 1991; Chakraborty et al., 1991; Lassar et al., 1991), it is possible that transgene $\mathrm{MyoD}$ in these studies directly transactivates skeletal genes in cardiac myocytes. Alternatively, MyoD may initiate a more complex, combinatorial set of changes that ultimately culminates in transcription of the suite of skeletal-specific differentiation genes. This issue of direct versus indirect activation remains unresolved for MyoD, even in the relatively simpler setting of clonal cell lines in culture, and it is quite possible that MyoD can serve more than one distinct function prior to and during overt expression of skeletal differentiation genes. In our

Fig. 5. Western blot analysis of whole heart homogenates. The embryonic MHC expressed by MuD 14 and MuD 42 hearts was identified on the basis of electrophoretic mobility and reaction with the embryonic MHC-specific mAb BF-45 (Schiaffino et al., 1988; Smith and Miller, 1992). In addition to the embryonic MHC isoform, MuD 42 heart expressed the perinatal MHC isoform, as is indicated by reaction with the perinata//Type II-specific mAb F47 (Miller, 1990; shown) and with the perinatalspecific mAb BF-34 (Smith and Miller, 1992; data not shown). Both the transgenic and non-transgenic hearts expressed the normal complement of cardiac MHC isoforms, identified by electrophoretic mobility and reaction with the general muscle MHC antibody F59 (top panel, lower bands; Miller, 1990). studies, the observed activation of myogenin in all phenotypically affected transgenics lends some weight to more complex models.

These studies also show that fetal cardiac myocytes

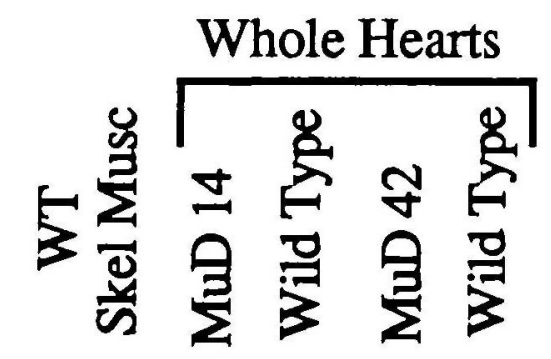

\section{All Myosin Heavy Chains}

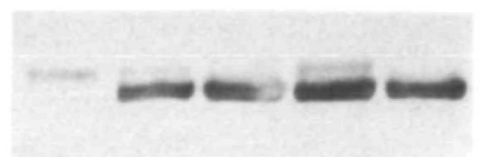

Embryonic MHC

Perinatal/Type II MHCs

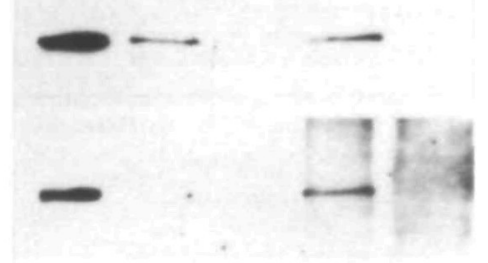

$\begin{array}{lllll}1 & 2 & 3 & 4 & 5\end{array}$ 
contain whatever molecular machinery is necessary for at least partial function of MyoD. A corollary of these findings is that repression - whether active or passive in mechanism - of endogenous MyoD expression is important for normal cardiac development, lest the disruption of cardiogenesis observed here occur in wildtype animals. Such repression may be responsible for the inability of MyoD encoded by the transgene (under MCK regulation) to activate its endogenous counterpart (and perhaps the endogenous Myf-5 and MRF4/herculin/Myf- 6 genes as well). If so, this would imply that the myogenin gene must be subject to less stringent repression than its three relatives, because it was the only endogenous myogenic regulatory gene to be activated by ectopic MyoD in heart. As myogenin is also the only myogenic regulator always activated in all cultured skeletal myocytes (Olson, 1990; Emerson, 1990 ) and is cross-activated by transfection of any member of the MyoD family (Edmondson and Olson, 1989; Thayer et al., 1989; Braun et al., 1989a; Rhodes and Konieczny, 1989; Miner and Wold, 1990), the myogenin gene may be a common target for activation by upstream myogenic regulators at the onset of differentiation.

Our results provide an interesting comparison with those obtained by Gurdon and colleagues. They ectopically expressed either Xenopus MyoD or Myf-5 or both by injecting the corresponding RNA into early Xenopus blastomeres (Hopwood and Gurdon, 1990; Hopwood et al., 1991). Subsequently, animal caps were dissected away from endoderm and presumptive mesoderm and cultured; these isolated animal caps would normally give rise exclusively to ectodermal derivatives. In the injected cultured caps, endogenous MyoD was activated, and sarcomeric actin RNA was detected. This muscle-specific gene expression waned, however, and the isolated caps eventually differentiated normally into epidermis. Here, $\mathrm{MCK} / \mathrm{MyoD}$ transgenic hearts clearly exhibited a partial skeletal muscle phenotype at both RNA and protein levels, but by examination of tissue sections or of cardiocytes cultured from transgenic hearts, we have found no multinucleated myotubes characteristic of mature skeletal muscle fibers. The extent of conversion to the skeletal phenotype may be limited to a subset of cells, and this might preclude cell fusion into myotubes because neighboring cells would not often be affected. Higher resolution studies of individual cardiocytes for expression of MyoD, myogenin, and skeletal structural components will be useful for understanding the extent of and limitations on conversion from the cardiac to the skeletal muscle phenotype. In any case, disruption at the cellular level is sufficiently profound to cause morphological changes in the organ and ultimately death. While we do not know the cause of death, the pumping defect observed in transgenic hearts removed from the fetus suggests that cardiac insufficiency, which is expected to become increasingly detrimental as the fetus grows larger, may be the cause. For the purposes of this study, however, the organismic level phenotype is peripheral to the primary results, which are that MyoD can redirect the differentiation pathway of cardiac myocytes in the animal.

MyoD is viewed as a positive regulator of determination because it is expressed in undifferentiated, proliferating myogenic precursors (Davis et al., 1987). However, it is not yet known whether MyoD has any essential, active regulatory role in such cells, or if its mere presence specifies the determined state. This determination issue is relevant here because transgene MyoD was expressed under the direction of MCK regulatory sequences, and MCK RNA from the endogenous gene is first detected in the heart on E13 (Lyons et al., 1991). The heart is a well-formed, beating organ by this time, and MCK-expressing cardiac myocytes are already substantially differentiated along the cardiac pathway (Rugh, 1968). MyoD-expressing cardiocytes may differentiate only partially along the skeletal pathway because they have not previously executed early skeletal myoblast determination functions, should these exist. Alternatively, cardiac-specific differentiation may simply interfere with full expression of the skeletal program. This is consistent with cell culture experiments in which MyoD-transfected melanoma and neuroblastoma cells do not become exclusively myogenic, but co-express some skeletal functions together with their original differentiation markers (Weintraub et al., 1989). Finally, death of the fetus may interrupt the terminal steps of skeletal muscle differentiation. Future transgenic experiments in which MyoD family regulators are specifically expressed at earlier points in cardiac development and in other cell lineages are expected to provide additional insights into their regulatory potential in different cellular environments.

We thank J. Buskin, A. Lassar, E. Olson, and J. Johnson for plasmids; T. Wilkie for heart cDNA; D. Laird, S. Schiaffino, J. Leger, and Z. Kaprielian for antibodies; J. Manning, J. Dausman, J. Johnson, S. T. Trivedi, and J.-P. Revel for assistance; L. Kedes, D. Anderson, N. Davidson, and P. Sternberg for comments; and the Wold group for their help and insights. J. H. M. was supported by a NSF Graduate Fellowship and by the NIH. This work was funded by grants from the Lucille P. Markey Charitable Trust, the Muscular Dystrophy Association, and the NIH to B. W. and a grant from the NIH to J. B. M. J. B. M. is an Established Investigator of the American Heart Association.

\section{References}

Bober, E., Lyons, G. E., Braun, T., Cossu, G., Buckingham, M. and Amold, H.-H. (1991). The muscle regulatory gene, $M y f-6$, has a biphasic pattern of expression during early mouse development. $J$. Cell Biol. 113, 1255-1265.

Braun, T. and Arnold, H. H. (1991). The four human muscle regulatory helix-loop-helix proteins Myf-3 - Myf6 exhibit similar hetero-dimerization and DNA binding properties. Nuc. Acids Res. 19, 5645-5651.

Braun, T., Bober, E., Buschhausen-Denker, G., Kotz, S., Grzeschik, K.-H. and Arnold, H. H. (1989a). Differential expression of myogenic determination genes in muscle cells: possible autoactivation by the $M y f$ gene products. EMBO J. 8, 3617-3625. 
Braun, T., Bober, E., Winter, B., Rosenthal, N. and Arnold, H. H. (1990). Myf-6, a new member of the human gene family of myogenic determınation factors: evidence for a gene cluster on chromosome 12. $E M B O$ J. 9, 821.831.

Braun, T., Buschhausen-Denker, G., Bober, E., Tannich, E. and Arnold, H. H. (1989b). A novel human muscle factor related to but distinct from MyoD1 induces myogenic conversion in 10T1/2 fibroblasts. $E M B O$ J. 8, 701-709.

Brennan, T. J. and Olson, E. N. (1990). Myogenin resides in the nucleus and acquires high affinity for a conserved enhancer element on heterodimerization. Genes Dev. 4, 582-595.

Chakraborty, T., Brennan, T. and Olson, E. (1991). Differential trans-activation of a muscle-specific enhancer by myogenic helixloop-helix proteins is separable from DNA binding. J. Biol. Chem. 266, 2878-2882.

Choi, J., Costa, M. L., Mermelstein, C. S., Chagas, C., Holtzer, S. and Holtzer, H. (1990). MyoD converts pnmary dermal fibroblasts, chondroblasts, smooth muscle, and retinal pigmented epithelial cells into striated mononucleated myoblasts and multinucleated myotubes. Proc. natn. Acad. Sci. USA 87, 7988-7992.

Chomczynski, P. and Sacchi, N. (1987). Single-step method of RNA isolation by acid guanidinium thiocyanate-phenol-chloroform extraction. Anal. Biochem. 162, 156-159.

Davis, R. L., Cheng, P.-F., Lassar, A. B. and Weintraub, H. (1990). The MyoD DNA binding domain contains a recognition code for muscle-specific gene activation. Cell 60, 733-746.

Davis, R. L., Weintraub, H. and Lassar, A. B. (1987). Expression of a single transfected cDNA converts fibroblasts to myoblasts. Cell 51, $987-1000$

Edmondson, D. G. and Olson, E. N. (1989). A gene with homology to the myc similarity region of MyoD1 is expressed during myogenesis and is sufficient to activate the muscle differentiation program. Genes Dev. 3, 628-640.

Emerson, C. P. (1990). Myogenesis and developmental control genes. Curr. Opinion in Cell Biol. 2, 1065-1075.

Evans, D., Miller, J. B. and Stockdale, F. E. (1988). Developmental patterns of expression and coexpression of myosin heavy chains in atria and ventricles of the avian heart. Devl Biol. 127, 376-383.

Florini, J. R. and Magri, K. A. (1989). Effects of growth factors on myogenic differentiation. Am. J. Physiol. (Cell Physiol.) 256 (25), C701-C711.

Hinterberger, T. J., Sassoon, D. A., Rhodes, S. J. and Koniecmy, S. F. (1991). Expression of the muscle regulatory factor MRF4 during somite and skeletal myofiber development. Devl Biol. 147, 144-156.

Hogan, B., Costantini, F. and Lacy, E. (1986). Manipulating the Mouse Embryo. New York: Cold Spring Harbor Laboratory.

Hopmood, N. D. and Gurdon, J. B. (1990). Activation of muscle genes without myogenesis by ectopic expression of $\mathrm{MyoD}$ in frog embryo cells. Nature 347, 197-200.

Hoprood, N. D., Puck, A. and Gurdon, J. B. (1991). Xenopus Myf-5 marks early muscle cells and can activate muscle genes ectopically in early embryos. Development 111, 551-560.

Jaynes, J. B., Johnson, J. E., Buskin, J. N., Gartside, C. L. and Hauschka, S. D. (1988). The muscle creatine kinase gene is regulated by multiple upstream elements, including a musclespecific enhancer. Molec. cell. Biol. 8, 62-70.

Johnson, J. E. (1988). Ph. D. thesis, University of Washington, Seattle.

Johnson, J. E., Wold, B. J. and Hauschka, S. D. (1989). Muscle creatine kinase sequence elements regulating skeletal and cardiac muscle expression in transgenic mice. Molec. cell. Biol. 9, 33933399.

Kramer Jr, A. W. and Marks, L. S. (1965). The occurrence of cardiac muscle in the pulmonary veins of rodentia. J. Morph. 117, 135-150.

Laird, D. W. and Revel, J.-P. (1991). Biochemical and immunochemical analysis of the arrangement of connexin 43 in rat gap junction membranes. J. Cell Sci. 97, 109-117.

Lassar, A. B., Buskin, J. N., Lockshon, D., Davis, R. L., Apone, S., Hanschka, S. D. and Weintraub, H. (1989). MyoD is a sequencespecific DNA binding protein requiring a region of myc homology to bind to the muscle creatine kinase enhancer. Cell 58, 823-831.

Lassar, A. B., Davis, R. L., Wright, W. E., Kadesch, T., Murre, C. Voronova, A., Baltimore, D. and Welntraub, H. (1991). Functional activity of myogenic $\mathrm{HLH}$ proteins requires hetero-oligomerization with E12/E47-like proteins in vivo. Cell 66, 305-315.

Leader, D. P., Gall, I. and Campbell, P. C. (1986). The structure of a cDNA clone corresponding to mouse cardiac muscle actin mRNA. Biosci. Rep. 6, 741-747.

Lyons, G. E., Muhlebach, S., Moser, A., Masood, R., Paterson, B. M., Buckingham, M. E. and Perriard, J.-C. (1991). Developmental regulation of creatine kınase gene expression by myogenic factors in embryonic mouse and chick skeletal muscle. Development 113 , 1017-1029.

Miller, J. B. (1990). Myogenic programs of mouse muscle cell lines Expression of myosin heavy chain isoforms, MyoD1, and myogenin. J. Cell Biol. 111, 1149-1159.

Miner, J. H. and Wold, B. (1990). Herculin, a fourth member of the $M y o D$ family of myogenic regulatory genes. Proc. natn. Acad. Sci. USA 87, 1089-1093.

Miner, J. H. and Wold, B. J. (1991). c-myc inhibition of MyoD and myogenın-initiated myogenic differentiation. Molec. cell. Biol. 11, 2842-2851

Olson, E. N. (1990). MyoD family: a paradigm for development? Genes Dev. 4, 2104-2111.

Ott, M.-O., Bober, E., Lyons, G., Arnold, H. and Buckingham, M. (1991). Early expression of the myogenic regulatory gene, myf-5, in precursor cells of skeletal muscle in the mouse embryo. Development 111, 1097-1107.

Piette, J., Bessereau, J.-L., Huchet, M. and Changeux, J.-P. (1990). Two adjacent MyoD1-binding sites regulate expression of the acetylcholine receptor $\alpha$-subunit gene. Nature 345, 353-355

Rhodes, S. J. and Konleczny, S. F. (1989). Identification of MRF4: A new member of the muscle regulatory factor gene family. Genes Dev. 3, 2050-2061.

Rosenthal, N., Berglund, E. B., Wentworth, B. M., Donoghue, M., Winter, B., Bober, E., Braun, T. and Arnold, H.-H. (1990). A highly conserved enhancer downstream of the human MLC1/3 locus is a target for multiple myogenic determination factors. Nuc. Acids Res. 18, 6239-6246.

Rugh, R. (1968). The Mouse: Its Reproduction and Development. Minneapolis: Burgess Publishing Company.

Sartorelli, V., Webster, K. A. and Kedes, L. (1990). Muscle-specific expression of the cardiac $\alpha$-actin gene requires MyoD1, CArG-box binding factor, and Sp1. Genes Dev. 4, 1811-1822.

Sassoon, D. A., Garner, I. and Buckingham, M. (1988). Transcripts of $\alpha$-cardiac and $\alpha$-skeletal actins are early markers for myogenesis in the mouse embryo. Development 104, 155-164.

Sassoon, D., Lyons, G., Wright, W. E., Lin, V., Lassar, A. Weintraub, H. and Buckingham, M. (1989). Expression of two myogenic regulatory factors myogenin and MyoD1 during mouse embryogenesis. Nature 341, 303-307

Schafer, B. W., Blakely, B. T., Darlington, G. J. and Blau, H. M. (1990). Effect of cell history on response to helix-loop-helix family of myogenic regulators. Nature 344, 454-458.

Schiaffino, S., Gorza, L., Pitton, G., Saggin, L., Ausont, S., Sartore, S. and Lomo, T. (1988). Embryonic and neonatal myosin heavy chain in denervated and paralyzed rat skeletal muscle. Devl Biol. 127, $1-11$

Schlaffino, S., Gorza, L., Sartore, S., Saggin, L., Ausoni, S., Vianello, M., Gundersen, K. and Lomo, T. (1989). Three myosin heavy chain isoforms in type 2 skeletal muscle fibers. J. Musc. Res. Cell Motil. $10,197-205$

Schwartz, K., de la Bastie, D., Bouveret, P., Oliviero, P., Alonso, S. and Buckingham, M. (1986). $\alpha$-Skeletal muscle actin mRNA's accumulate in hypertrophied adult rat hearts. Circ. Res. 59, 551 555

Smith, T. H. and Miller, J. B. (1992). Distinct myogenic programs of embryonic and fetal mouse muscle cells: expression of the perinatal myosin heavy chain isoform in vitro. Devl Biol. 149, 16-26.

Tapscott, S. J., Davis, R. L., Thayer, M. J., Cheng, P.-F., Weintraub, H. and Lassar, A. B. (1988). MyoD1: a nuclear phosphoprotein requiring a myc homology region to convert fibroblasts to myoblasts. Science $242,405-411$.

Thayer, M. J., Tapscott, S. J., Davis, R. L., Wright, W. E., Lassar, A. B. and Weintraub, H. (1989). Positive autoregulation of the myogenic determination gene MyoD1. Cell 58, 241-248.

Weintraub, H., Davis, R., Tapscott, S., Thayer, M., Krause, M. 
Benezra, R., Blackwell, T. K., Turner, D., Rupp, R., Hollenberg, S., Zhuang, Y. and Lassar, A. (1991). The myoD gene family: nodal point during specification of the muscle cell lineage. Science 251, 761-766.

Weintraub, H., Tapscott, S. J., Davis, R. L., Thayer, M. J., Adam, M. A., Lassar, A. B. and Muller, A. D. (1989). Activation of musclespecific genes in pigment, nerve, fat, liver, and fibroblast cell lines by forced expression of MyoD. Proc. natn. Acad. Sci. USA 86 , 5434-5438.

Wright, W. E., Sassoon, D. A. and Lin, V. K. (1989). Myogenin, a factor regulating myogenesis, has a domain homologous to MyoD1. Cell 56, 607-617. 